\title{
Study of feto maternal outcome of teenage pregnancy at tertiary care hospital
}

\author{
Rita D.*, Kiran Naik, R. M. Desai, Sphurti Tungal
}

Department of Obstetrics and Gynecology, SDM Medical College, Dharwad, Karnataka, India

Received: 24 May 2017

Accepted: 31 May 2017

\section{*Correspondence:}

Dr. Rita D.,

E-mail: rita.vijayachandra@gmail.com

Copyright: () the author(s), publisher and licensee Medip Academy. This is an open-access article distributed under the terms of the Creative Commons Attribution Non-Commercial License, which permits unrestricted non-commercial use, distribution, and reproduction in any medium, provided the original work is properly cited.

\begin{abstract}
Background: Teenage pregnancy due to changing social conditions, it's important to study the implications of the maternal and fetal health. It is a serious health problem, more so in developing countries like India. Young mothers and newborns are at increased risk of anaemia, pre-eclampsia, increased rate of LSCS, PTVD, LBW, prematurity, NICU care, RDS, sepsis, IUGR. Hence, study is directed to identify the problems and their outcome.

Methods: Teenage pregnant ladies between 18 to 20 years were taken up for the study. Study duration was 1 year from January to December 2016, at SDM Medical College Dharwad. During this period, all cases were included in the study, irrespective of their booking and unbooking statuses after 28 weeks of pregnancy are taken.

Results: Study showed the incidence of teenage pregnancy is $10.26 \% .79 .2 \%$ of teenage mothers have varying grades of anaemia, $13.6 \%$ of women had eclampsia, $16.01 \%$ had preterm deliveries, LSCS rate were as high as $52 \%, 17.4 \%$ had instrumental deliveries, $12.5 \%$ were low birth weight neonates, $8.4 \%$ requiring NICU care and $2 \%$ were perinatal deaths due to prematurity, respiratory distress, sepsis.

Conclusions: As teenage pregnancy is associated with high risk of anaemia, pre-eclampsia, eclampsia, PTVD, instrumental delivery, high rate of LSCS, prematurity, low birth weight, perinatal death. It's important to reduce the teenage pregnancy by improving the socio-economic condition, education, public awareness, strict implementation of law, good ANC care, nutrition, access to contraceptive services, sex education.
\end{abstract}

Keywords: Anaemia, CPD, Eclampsia, PTVD, Teenage pregnancy

\section{INTRODUCTION}

In recent decade, adolescent pregnancy has become important health issue in a great number of countries, both developed and developing. ${ }^{1}$ WHO defines teenage pregnancy as any pregnancy from a girl who is 10 to 19 years of age, age being defined as her age at the time of delivery. ${ }^{2}$ Adolescent pregnancy rate is on rise, emerging as serious problem all over the world and more so in developing countries like India. It constitutes 11 percent of all the births worldwide and 23 percent of overall disease burden due to pregnancy and child birth due to improper prenatal care needed for monitoring of maternal and fetal development. ${ }^{3}$ The incidence of teenage pregnancy varies dramatically between the different countries, of which 90 percent is contributed by developing countries. ${ }^{4}$ Nevertheless teenage pregnancy and delivery rate is significantly less in developed countries compared to developing countries. ${ }^{5}$

Incidence of teenage pregnancy in India is 2 women out of every 1000 pregnancies. $^{6}$ Teenage pregnancy is associated with series of maternal and fetal complications. Anaemia, pre-eclampsia, eclampsia, preterm delivery, instrumental delivery, increased LSCS rate due to cephalopelvic disproportion and fetal distress are strongly associated maternal complications in teenage pregnancy. Fetal complications being prematurity, low 
birth weight, still birth, asphyxia, respiratory distress, birth trauma. Underdeveloped pelvis in adolescents makes them prone to have CPD and end up in caesarean delivery. As girls are still in growing period, pregnancy induces malnutrition leading to inadequate weight gain and low birth in neonates. Low birth weight and prematurity predisposes such children to several infant and childhood disorders and increased risk of mortality and morbidity. Good antenatal care by medical professional makes a big difference in outcome of teenage pregnancy, care provider should stress upon good nutrition, and anticipate the risks of medical disorders associated with it and intervene at the earliest.

The need for the study was to know the outcome of teenage pregnancy. To know the socio demographic profile of teenage pregnancies, and incidence. The objective of the study was to know the complications in the teenage pregnancies and outcome.

\section{METHODS}

The prospective study is conducted in SDMMCH, Sattur in department of OBG over a period of one year January to December 2016 and data will be analyzed. All pregnant women coming to either OPD or directly to labour theater were included in study group. History taken and examination done. Investigations collected i.e. hemoglobin, blood group, RH typing, serology, urine routine, RBS. Data collected regarding mode of delivery, whether vaginal delivery or caesarean delivery, full term vaginal delivery or preterm delivery, if LSCS then indication for LSCS, fetal outcome in terms of prematurity, RDS, low birth weight, still birth, anomalous fetus, NICU admission. Data analyzed.

\section{Inclusion criteria}

All pregnant women visiting OBG department SDMMC and H SATTUR.

- $\quad$ Age 18-20 years

- Primigravida/Multigravida

- Gestational age more than 28 weeks.

\section{Exclusion criteria}

- $\quad$ Age more than 20 years

\section{RESULTS}

Total number of deliveries in a study period 5112 (n). Table 1 describes: Among the 5112 deliveries in our institute 525 are teenage pregnancies contributing to $10.26 \%$, among them 204 had vaginal delivery contributing to $3.9 \%$ of vaginal deliveries and 221 underwent LSCS contributing to $4.32 \%$ of caesaren deliveries for various indications without much difference compared to adult mothers.

Table 1: Total number of deliveries.

\begin{tabular}{|lcc|cc|}
\hline & Teenage & More than 20 years \\
\hline $\begin{array}{l}\text { Total no. of } \\
\text { deliveries }\end{array}$ & 525 & $10.26 \%$ & 4687 & $91.68 \%$ \\
\hline $\begin{array}{l}\text { Vaginal } \\
\text { deliveries }\end{array}$ & 204 & $3.9 \%$ & 2453 & $47.98 \%$ \\
\hline LSCS & 221 & $4.32 \%$ & 2234 & $43.70 \%$ \\
\hline
\end{tabular}

Figure 1 show that incidence of teenage pregnancy in our institution is $10.26 \%(525)$, and adult were $91.678 \%$ (4687), $\mathrm{n}=5112$.

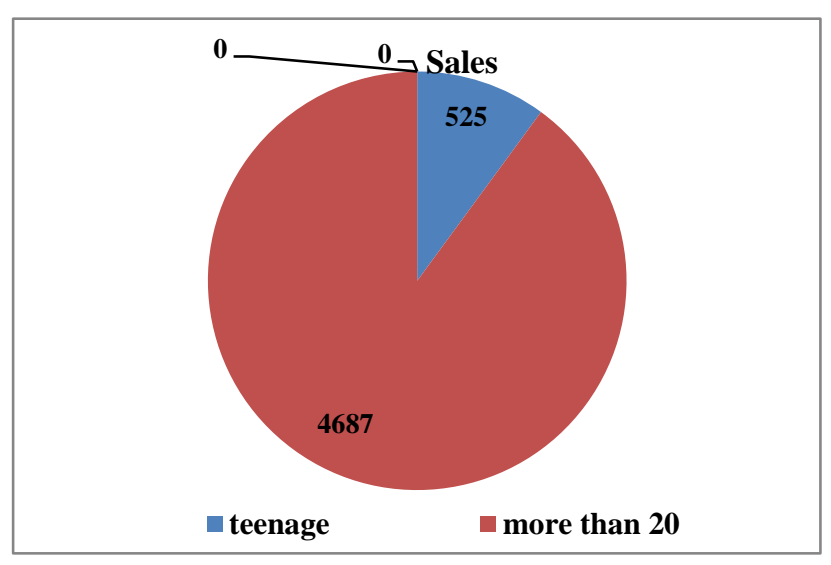

Figure 1: Incidence the of teenage pregnancy.

Table 2: Vaginal deliveries, total number of vaginal deliveries during study period being $2657 \mathrm{n}=5112$.

\begin{tabular}{|llllll|}
\hline & & FTVD & FTVD & PTVD & PTVD \\
\hline Age more than 19 yrs(2453) & FTVD & Vaccum & forceps & Without instrument & Forceps \\
\hline Teenage (204) & $171(83.0 \%)$ & $72(42.10 \%)$ & $2(1.16 \%)$ & $30(14.7 \%)$ & $4(1.02 \%)$ \\
\hline
\end{tabular}

Table 2 describes among 2657 vaginal deliveries during study period 204 were teenage deliveries, $83 \%$ had full term vaginal deliveries and $42.1 \%$ had vacuum assisted deliveries, 2 patient had forceps delivery.
Preterm delivery incidence being $14.7 \%(n=33)$ which is not significant compared to adult deliveries which is mentioned in Table 2 . 
Table 3: Complications associated with teenage pregnancy.

\begin{tabular}{|ll|l|}
\hline & No. of teenage pregnancy & $\%$ \\
\hline Anaemia & 336 & 79.2 \\
\hline Pre-eclampsia & 160 & 37.6 \\
\hline Eclampsia & 57 & 13.6 \\
\hline
\end{tabular}

Table 3 shows Incidence of anaemia in teenage mothers is more as high as $79.2 \%$. and pre-eclampsia contributing to $37 \%$ and eclamsia $13.6 \%$ which is significantly high compared to adult mothers in other studies as mentioned in discussion part.

Table 4: Neonatal outcome in teenage pregnancy (525).

\begin{tabular}{|c|c|c|}
\hline & No. of newborns & $\%$ \\
\hline Low birth weight & 53 & 12.5 \\
\hline Nicu admission & 35 & 8.4 \\
\hline Perinatal deaths & 8 & 2 \\
\hline
\end{tabular}

Table 4 shows neonatal outcome is poor in teenage mothers $(10.26 \%)$ as compared to adult mothers, low birth weight $12.5 \%$ contributing to main morbidity which is significant compared to mothers more than 19 years. $8.4 \%$ being NICU admission and $2 \%$ being perinatal mortality, which includes still births.

Table 5: Indications for LSCS VS others.

\begin{tabular}{|lll|}
\hline Indications & Number & $\%$ \\
\hline Cephalo pelvic Disproportion & 164 & 74.2 \\
\hline Pre-eclampsia and eclampsia & 28 & 12 \\
\hline Fetal distress & 21 & 9.4 \\
\hline $\begin{array}{l}\text { Malpresentations and Placental } \\
\text { causes }\end{array}$ & 8 & 3.5 \\
\hline
\end{tabular}

Table 5 shows the main indication contributing to caesarean delivery is cephalo pelvic disproportion in teenage pregnancy with $74.2 \%$ and Pre-eclampsia and eclampsia and fetal distress contributing to $12 \%$ and $9.4 \%$ each.

\section{Statistical analysis}

The collected demographic information, maternal and neonatal outcome, measures were interred in Microsoft excel sheet and the variables were summarized using number and percentages.

\section{DISCUSSION}

Teenage pregnancy exposes mothers to many health related complications and newborns to poor birth outcome. Adverse outcome of teenage pregnancy arises not only from physical and medical causes associated but also depends on individual, family, social, cultural, economic factors besides lack of access to health care, contraception, resources, education. Early registration of pregnancy and consumption of recommended number of iron and folic acid supplements was significantly lower in teenage mothers. This implies that teenage mothers are less careful about their pregnancy probably secondary to lack of awareness, maturityand other social factors. Majority of deliveries were by vertex presentation compared to grand multipara were breech presentation and malposition were seen frequently. Increased incidence of LSCS in teenage pregnancies and medical complications associated with it like anemia, PIH, and fetal complications being, prematurity, IUGR, Low birth weight are preventable factors.

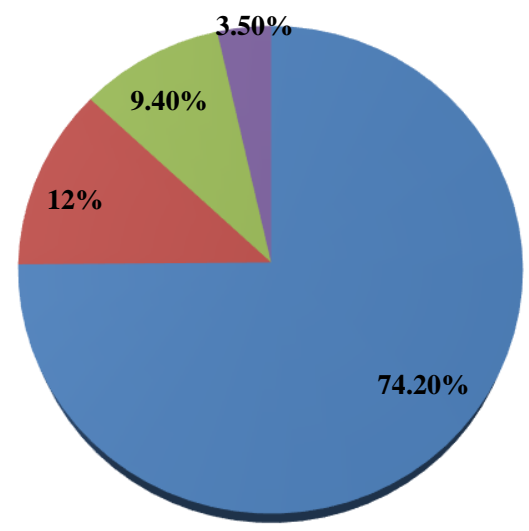

Sales

$\square$ cpd $\square$ pih $\square$ fetal distress $\square$ malpresentation and others

Figure 2: Indications for caesarean delivery in teenage mothers.

Teenage pregnancy remains major health issue in our country due to prevailing social dogmas, age old traditions and poor access to health care in remote rural areas, illiteracy leads to lack of knowledge about family planning and puts the adolescents at risk for early pregnancy. Education play major role in decreasing the incidence of teenage pregnancy and its attendant health risks and psychological issues.

Teenage mothers should be counselled to have regular ANCs for early detection of complications related to both mother and fetus. Adequate antenatal, intrapartum and post-partum as well as neonatal care can minimize the risk associated with child birth and its effect on maternal and child health.

So, it's important to reduce the incidence of teenage pregnancies in order to reduce the incidence of maternal and fetal morbidity associated with teenage pregnancy. Effect of teenage pregnancy remains for the teen mother and her child even after adjusting for those factors that increased the teenager's risk for pregnancy, such as growing up in poverty, having parents with low levels of educations, growing up in single parent family, having poor performance in school. Along with that it has its long-term implications on maternal health like chronic anaemia, risk of cervical cancer, risk of molar pregnancy 
and invasive mole, uterine prolapse, genital tract injuries like fistula, pelvic inflammatory disease, sexually transmitted diseases. Rate of caesarean delivery was high, predominant indication being cephalo pelvic disproportion, fetal distress, medical disorders associated like pre-eclampsia, eclampsia. Vaginal delivery was seen in cases with low birth weight baby's secondary to growth restriction or prematurity. Rate of instrumental deliveries was also high due to poor maternal efforts and underdeveloped pelvis. Medical disorders associated with teenage pregnancy contributed to some extent to the time and mode of in turn increases the fetal and neonatal complications. Significant number of neonates born to teenage mothers had low birth weight, probably due to malnutrition, medical diseases associated with pregnancy leading to intrauterine growth restriction and prematurity. Neonates born before term with IUGR were at increased risk of morbidity and mortality resulting from respiratory distress, immature organ systems, infections, hyperbilirubinemia, convulsion, difficult to strive, feeding difficulty, convulsions which will significantly affect the further development of the child. Due to promiscuity associated with teenage pregnancy risks associated with termination of pregnancy is also high like septic abortions, incomplete abortions and morbidity associated with it.

Incidence of teenage pregnancy in our study was $10.06 \%$, but other studies showed the incidence from $8.3-23.4 \%{ }^{7}$ In present study it came across two unmarried mothers even though its common practice to undergo abortion in unmarried women. Among the teenage mothers $3.02 \%$ were multi gravidas, with $0.95 \%$ being parous. Incidence of anemia was $79.2 \%$ in our study, $65-76 \%$ in similar studies. Pre-eclampsia contributed to $37 \%$ in our study where as other studies showed range between $28-35 \%$. Other studies have shown to have increased incidence if preterm delivery in studies but there was no significant difference. There is significant rise in instrumental deliveries as shown in other studies in teenage mother contributing up to $42 \%$ probably due to inadequate pelvis. There is no much difference between caesarean delivery rates in our study as the number of caesarean delivery is increasing in women above age of 19 years for many other reasons like fetal distress, elderly primigravida, GDM on insulin, severe pre-eclampsia, previous LSCS, multiple gestation with malpresentations and maternal request. But cephalo pelvic disproportion is the leading indication for caesarean in teenage mothers.

Other indications for caesarean delivery are preeclamsia and related complications $12 \%$, fetal distress $9.4 \%$, malpresentations and placental causes $3.7 \%$ in our study. Perinatal outcome in teenage mothers is poor compared to adult mothers in terms of low birth weight, and respiratory distress due to difficult delivery. The incidence of low birth weight in $12 \%$ and NICU admission rate is $8.4 \%$, and perinatal mortality is $2 \%$ which is comparable other studies where low birth weight is $38.9 \%$ and perinatal mortality is $5.1 \% .^{8}$
In our study, we had one anomalous fetus and 2 freshes still births and 1 macerated still births, which are comparable to other studies. ${ }^{9}$

Table 6: Comparison between present study and other studies.

\begin{tabular}{|llll|}
\hline & $\begin{array}{l}\text { Present } \\
\text { study }\end{array}$ & $\begin{array}{l}\text { Ashok } \\
\text { et al }\end{array}$ & $\begin{array}{l}\text { Ekachai et } \\
\text { al }\end{array}$ \\
\hline anaemia & $79.2 \%$ & $62.9 \%$ & $10 \%$ \\
\hline preeclamsia & $37.6 \%$ & $20.8 \%$ & $22 \%$ \\
\hline preterm & $14.7 \%$ & $51.8 \%$ & $12 \%$ \\
\hline Lscs & $52 \%$ & $32.2 \%$ & $18.7 \%$ \\
\hline
\end{tabular}

\section{CONCLUSION}

India is growing to be a most populous country in world, and teenage pregnancy is likely to aggravate the problem. As teenage pregnancy is associated with increased incidence of preeclampsia, eclampsia, preterm delivery, increased incidence of instrumental deliveries and LSCS due to cephalopelvic disproportion, neonatal complications, increased neonatal morbidity and mortality mainly due to low birth weight was noted in babies delivered to teenage mothers.

Present study recommends that in order to improve the teenage health periodic information, education, community activities, ANC camps to be held at primary health care centers. Public awareness to be created regarding health of teenage girls and right of education to girls. Law against early marriage i.e. less than 18 years, need to be implemented strictly which will prevent substantiate number of teenage pregnancies, in turn obstetric complications, maternal and neonatal morbidity and mortality. In order to reduce the teenage pregnancies WHO Guidelines as stated below on preventing early pregnancy and poor reproductive outcomes amongst adolescents in developing countries has been recommended. Reduce the number of marriage before 18 years. Prevent pregnancy before age of 20 years. Increased access of contraception. Reduce unsafe abortions among adolescents. Increased use of skilled antenatal check-up, child birth, post-natal care.

Funding: No funding sources

Conflict of interest: None declared

Ethical approval: The study was approved by the Institutional Ethics Committee

\section{REFERENCES}

1. Doddihal CR, Katti SM, Mallapur MD. Teenage pregnancy outcome in a rural area of south India. Int J Med Public Health. 2015;5(3):222-4.

2. WHO, United nations population fund: Married adolescents: no place of safety, Geneva: WHO, UNFPA; 2006

3. Adolescent pregnancy- Issue in adolescent health and development; WHO discussion paper on adolescents, 
WHO; 2004:86. Available at http://apps.who.int/iris/bitstream/10665/42903/1/924 1591455_eng.pdf.

4. Allan Guttmachu institute. Risks and realities of early child bearing. Allan Guttmachu. 2000

5. UNICEF. A league table of teenage birth in rich nation. Innocenti Report Card. Florence, Italy; 2001;3. Available at https://www.unicefirc.org/publications/pdf/repcard3e.pdf

6. Government of india, National family health survey 2005-2006:3-24. Available at http://dhsprogram.com/pubs/pdf/FRIND3/FRIND3Vol1andVol2.pdf

7. Talawar S, Venkatesh G. Outcome of teenage pregnancy. IOSR J Dental Med Sci. 2013;6(6):81-3.
8. Mukhopadhyay P, Chaudhuri RN, Paul B. Hospitalbased perinatal outcomes and complications in teenage pregnancy in India. J Health, Population Nutrition. 2010:28(5)|:494-500.

9. Kumar A, Singh T, Basu S, Pandey S, Bhargava V. Outcome of teenage pregnancy. Indian J Pediatr. 2007;74(10):927-31.

Cite this article as: Rita D, Naik K, Desai RM, Tungal S. Study of feto maternal outcome of teenage pregnancy at tertiary care hospital. Int J Reprod Contracept Obstet Gynecol 2017;6:2841-5. 